\title{
Gallstone ileus in an already cholecystectomized patient
}

\author{
Andrea Rossetti, Nicolas Christian Buchs, Vincent Ott, Philippe Morel
}

\section{CASE REPORT}

A 91-year-old female was admitted to the emergency department with a three-day history of abdominal pain and vomiting. She reported having similar but lower in intensity episodes in the past. Her past medical history was significant for an open cholecystectomy, performed many years ago. No surgical details were available. She also had numerous comorbidities which included type II diabetes, chronic heart failure, and hypertension.

On clinical examination, the patient was non-febrile and hemodynamically stable. Tenderness of lowers quadrants and increased bowel sounds were also reported. Blood tests of the patient showed increase inflammatory parameters, (PCR 67 and with cells count 19.600).

Computed tomography (CT) scan showed an image compatible with a foreign body localized in the distal portion of small bowel, not far away from the ileocecal valve (Figure 1A-B). Due to the importance and the persistence of clinical symptoms, we decided to perform an exploratory laparotomy. Finally, two gallstones (3x5 $\mathrm{cm}$ and $2 \times 3 \mathrm{~cm}$ ) (Figure 2) were found $10 \mathrm{~cm}$ from the ileocecal valve. An intestinal resection was then performed with direct anastomosis.

The postoperative course was remarkable for heart failure with respiratory distress and pulmonary infection. The length of stay was 30 days.

Andrea Rossetti ${ }^{1}$, Nicolas Christian Buchs ${ }^{2}$, Vincent Ott², Philippe Morel $^{2}$

Affiliations: ${ }^{1}$ Clinic for Visceral Surgery and Transplantation, Department of Surgery, University Hospital of Geneva, Switzerland, Clinic for Surgery, Kantonspital St. Gallen, Switzerland; ${ }^{2}$ Clinic for Visceral Surgery and Transplantation, Department of Surgery, University Hospital of Geneva, Switzerland.

Corresponding Author: Dr. Andrea Rossetti, Clinic for Visceral Surgery and Transplantation University Hospital of Geneva, Clinic for Surgery Kantonspital St. Gallen. Switzerland; E-mail: andrea.rossetti83@gmail.com

Received: 03 December 2012

Accepted: 18 February 2013

Published: 01 June 2014
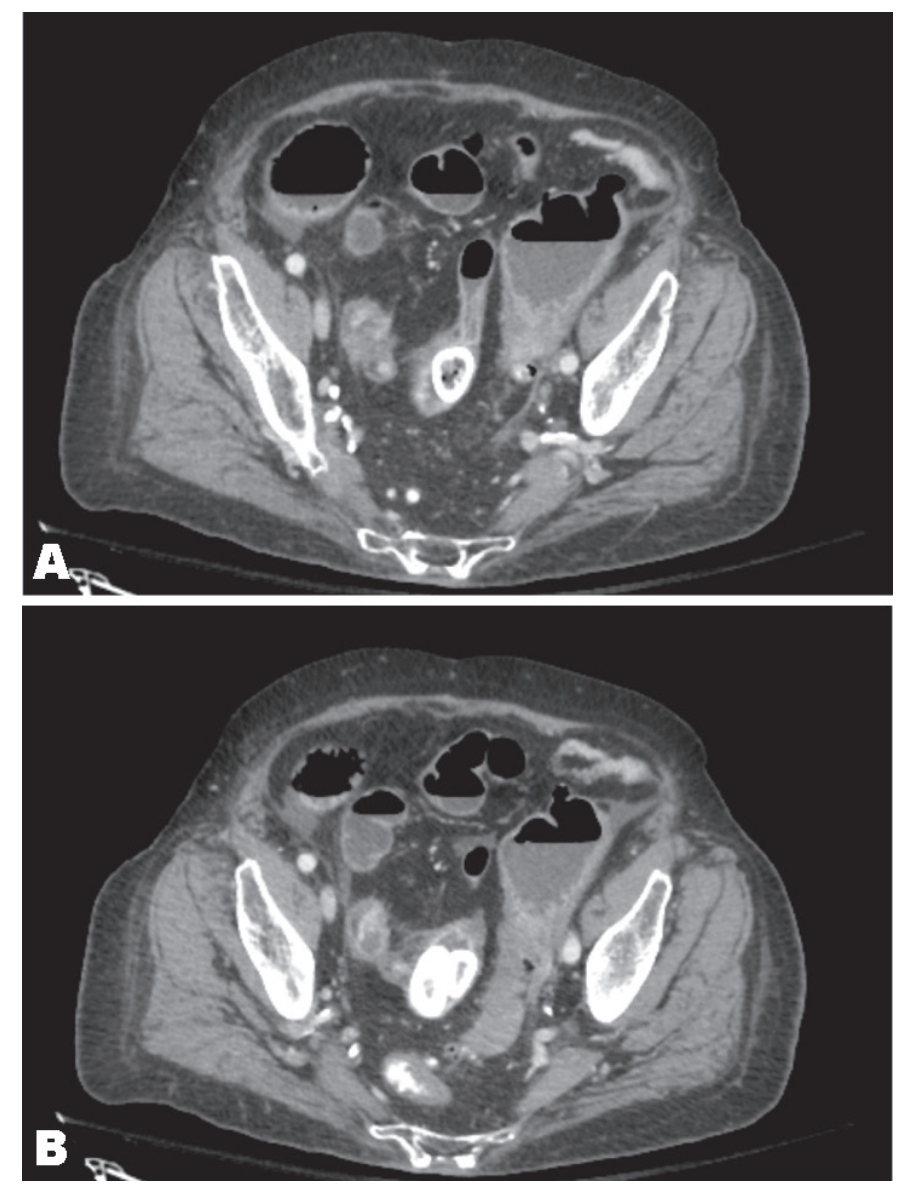

Figure 1: (A, B) Computed tomography scan showing an image compatible with a foreign body localized in the distal small bowel.

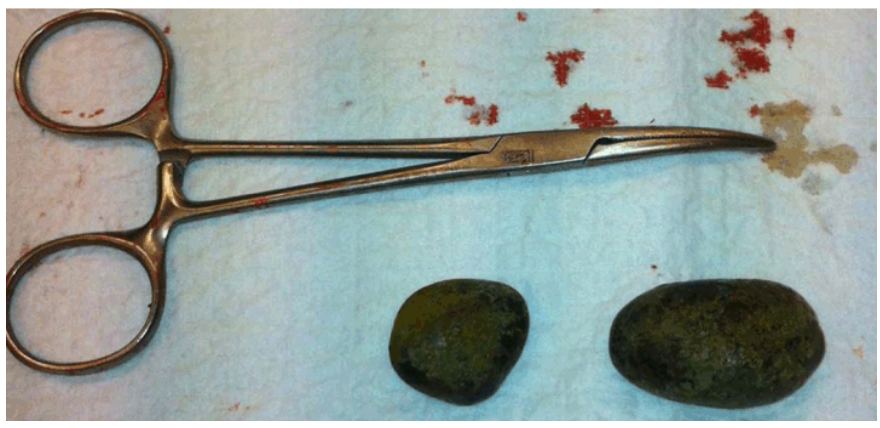

Figure 2: Perioperative image of two gallstones $(3 \times 5 \mathrm{~cm}$ and $2 \times 3 \mathrm{~cm})$. 


\section{DISCUSSION}

Gallstone ileus is a rare complication of cholecystitis that occurs in $0.5 \%$ of cases [1]. It usually occurs because of a cholecystoenteric fistula, allowing the passage of a large stone in the intestine [2, 3]. It can happen after sphincterotomy as well, but remains an uncommon complication. Unfortunately in our patient, we had no operative details of the previous cholecystectomy, performed many years ago.

While uncommon in general population, in patients older than 65 years, it is the cause of $25 \%$ of all nonstrangulated small bowel obstruction [1]. In the past, the mortality rate due to gallstone ileus was nearly $50 \%$, but in recent years has improved to about $8-18 \%[1,3-5]$. This relatively high morality is related to the advanced age of the typical patient. Moreover, in a series of 37 patients showed that $62 \%$ of patients had serious concomitant diseases [3].

In addition, the diagnosis can be challenging. At admission, it is usually missed (in up to $54 \%$ of patients) and the diagnosis is mostly made during surgery $[1,3-6]$. A plain abdominal radiography can show a calcified mass with obstructive signs. Classically, the Rigler's triad is the presence of an aerobilia, a mechanical bowel obstruction and an ectopic gallstone [2]. In case of doubt, a computed tomography is usually performed. It confirms the diagnosis in most of patients, as it was our case. Our patient had already had a cholecystectomy, the classical triad was not present. Yet, the other signs were clearly noted.

The location of the obstruction is classical as well. The distal ileon is the most frequent site involved $[3,6,7]$. The presence of several gallstones is not uncommon as well. In $16 \%$ of cases, more than one stone can be found [3].

Concerning the management, surgery is required to relieve the obstruction. The removal of impacted stone is mandatory, and does not necessitate always an intestinal resection. Yet, in our case, the small bowel showed suffering signs and a resection was considered as the safer option. However, cases of gallstone intestinal obstruction without a biliodigestive fistula have been described [8].

A rare occurrence is the gallstone ileus after lost biliary calculi. In literature, two cases of intestinal obstruction when a "lost" calculus after a difficult laparoscopic cholecystectomy migrated through the jejunal wall are reported $[9,10]$.

In case of cholecystoenteric fistula, different approaches can be considered. A one-stage procedure consisting of the removal of the impacted stone, fistula repair and cholecystectomy can be performed, but may be associated with a higher complications rate. On the other hand, a two-stage procedure consisting of enterolithotomy followed by elective biliary surgery is usually considered as safer $[1,3]$. However, in our case, there was only the impacted stone to treat, since the gallbladder was already removed. It would have been interesting to know exactly what happened during the surgery at that time and whether a fistula was present or not.

\section{CONCLUSION}

In conclusion, a cholecystectomy does not prevent the occurrence of a gallstone ileus. This pathology, even if uncommon, has to be considered when the plain abdominal radiography shows a mechanical obstruction with an ectopic calcified mass. The treatment remains prompt surgery, especially in fragile patients, that constitute majority of the population at risk for this pathology.

\section{How to cite this article}

Rossetti A, Buchs NC, Ott V, Morel P. Gallstone ileus in an already cholecystectomized patient. Int $\mathrm{J}$ Case Rep Images 2014;5(6):453-455.

doi:10.5348/ijcri-201456-CL-10044

$* * * * * * * * *$

\section{Author Contributions}

Andrea Rossetti - Substantial contributions to conception and design, Acquisition of data, or analysis and interpretation of data, Drafting the article or revising it critically for important intellectual content, Final approval of the version to be published

Nicolas Christian Buchs - Substantial contributions to conception and design, Acquisition of data, Analysis and interpretation of data, Drafting the article or revising it critically for important intellectual content, Final approval of the version to be published

Vincent Ott - Substantial contributions to conception and design, Acquisition of data, Analysis and interpretation of data, Drafting the article or revising it critically for important intellectual content, Final approval of the version to be published

Philippe Morel - Substantial contributions to conception and design, Acquisition of data, or analysis and interpretation of data, Drafting the article or revising it critically for important intellectual content, Final approval of the version to be published

\section{Guarantor}

The corresponding author is the guarantor of submission.

\section{Conflict of Interest}

Authors declare no conflict of interest.

\section{Copyright}

(C) 2014 Andrea Rossetti et al. This article is distributed under the terms of Creative Commons Attribution License which permits unrestricted use, distribution 
and reproduction in any medium provided the original author(s) and original publisher are properly credited. Please see the copyright policy on the journal website for more information.

\section{REFERENCES}

1. Reisner RM, Cohen JR. Gallstone ileus: A review of 1001 reported cases. Am Surg 1994;60(6):441-6.

2. Buchs NC, Azagury D, Chilcott M, Nguyen-Tang T, Dumonceau JM, Morel P. Bouveret's syndrome: Management and strategy of a rare cause of gastric outlet obstruction. Digestion 2007;75(1):17-9.

3. Clavien PA, Richon J, Burgan S, Rohner A. Gallstone ileus. Br J Surg 1990 Jul;77(7):737-42.

4. Rodriguez Hermosa JI, Codina Cazador A, Girones Vila J, Roig Garcia J, Figa Francesh M, Acero Fernandez D. Gallstone Ileus: results of analysis of a series of 40 patients. Gastroenterol Hepatol 2001;24(10):489-4. [Article in Spanish].

5. Pavlidis TE, Atmatzidis KS, Papaziogas BT, Papaziogas TB. Management of gallstone ileus. J Hepatobiliary Pancreat Surg 2003;10(4):299-302.

6. Nakao A, Okamoto Y, Sunami M, Fujita T, Tsuji T. The oldest patient with gallstone ileus: Report of a case and review of 176 cases in Japan. Kurume Medical Journal 2008;55(1-2):29-33.

7. Ivanov I, Beuran M, Venter MD, et al. Gallstone ileus after laparoscopic cholecystectomy. J Med Life 2012 Sep 15;5(3):335-41.

8. Saedon M, Gourgiotis S, Salemis NS, Majeed AW, Zavos A. Gallstone ileus one quarter of a century post cholecystectomy. Annals of Hepatology 2008;7(3):258-9.

9. Draganic BD, Reece-Smith H. Gallstone ileus without a gallbladder. Ann R Coll Surg Engl 1997;79(3):231-2.

10. Dittrich K, Weiss H. Ileus of the small intestine caused by a lost gallstone! A late complication of laparoscopic cholecystectomy. Chirurg 1995;66(4):443-5. [Article in German].

Access full text article on other devices

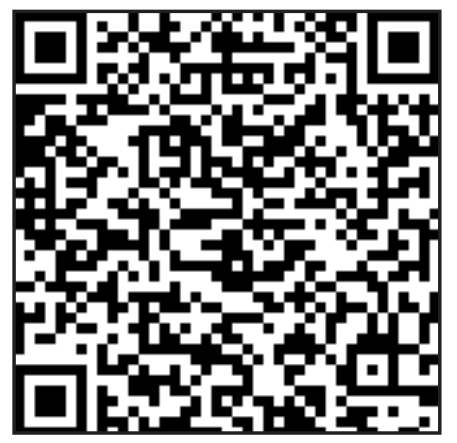

Access PDF of article on other devices

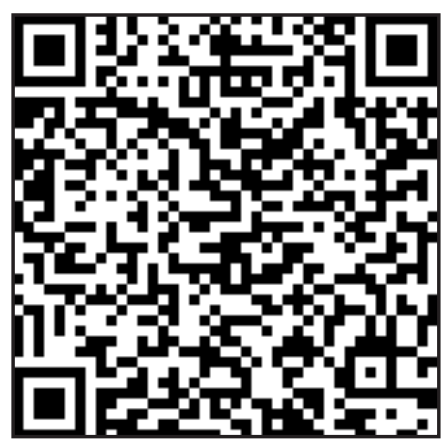

